\title{
Perinatal Risks in “Late Motherhood” Defined Based On Parity and Preterm Birth Rate - an Analysis of the German Perinatal Survey (20th Communication)
}

\section{Perinatale Risiken bei „später Mutterschaft“ definiert aufgrund von Parität und Frühgeborenenrate - Analyse der Deutschen Perinatalerhebung (20. Mitteilung)}

Authors

Affiliations
V. Schure ${ }^{1}$, M. Voigt ${ }^{2}$, R. L. Schild ${ }^{1}$, V. Hesse ${ }^{2}$, M. Carstensen ${ }^{3}$, K. T. M. Schneider ${ }^{4}$, S. Straube ${ }^{5}$

Department of Obstetrics and Gynaecology, Diakonische Dienste Hannover, Hannover

2 German Center for Growth, Development, and Health Encouragement during Childhood and Youth, Berlin

3 Jerusalem Hospital, Hamburg

${ }^{4}$ Section of Perinatal Medicine, Department of Obstetrics and Gynaecology, Technical University of Munich, Munich

${ }^{5}$ Department of Occupational, Social and Environmental Medicine, University Medical Center Göttingen, Göttingen
Schlüsselwörter

- späte Mutterschaft

- Parität

- Frühgeborenenrate

- perinatale Risiken

- Deutsche Perinatalerhebung

Key words

- late motherhood

0 parity

- preterm birth rate

- perinatal risks

- German Perinatal Survey

$\begin{array}{ll}\text { received } & 3.1 .2011 \\ \text { revised } & 24.5 .2011 \\ \text { accepted } & 14.11 .2011\end{array}$

Bibliography

DOI http://dx.doi.org/

10.1055/s-0031-1280407

Geburtsh Frauenheilk 2012; 72 :

49-55 ๑ Georg Thieme

Verlag KG Stuttgart · New York ISSN 0016-5751

\section{Correspondence}

PD Dr. Dr. Manfred Voigt

German Center for Growth,

Development and Health

Encouragement during

Childhood and Youth, Berlin

Working Group

Kükensteg 13

18069 Rostock-Sievershagen

voim13@t-online.de

\section{Abstract}

$\nabla$

Aim: "Late motherhood" is associated with greater perinatal risks but the term lacks precise definition. We present an approach to determine what "late motherhood" associated with "high risk" is, based on parity and preterm birth rate. Materials and Methods: Using data from the German Perinatal Survey of 1998-2000 we analysed preterm birth rates in women with zero, one, or two previous live births. We compared groups of "late" mothers (with high preterm birth rates) with "control" groups of younger women (with relatively low preterm birth rates). Data of 208342 women were analysed. For women with zero (one; two) previous live births, the "control" group included women aged 22-26 (27-31; 2933) years. Women in the "late motherhood" group were aged $>33(>35 ;>38)$ years.

Results: The "late motherhood" groups defined in this way were also at higher risk of adverse perinatal events other than preterm birth. For women with zero (one; two) previous live births, normal cephalic presentation occurred in $89 \%$ (92.7\%; $93.3 \%$ ) in the "control" group, but only in $84.5 \%$ (90\%; 90.4\%) in the "late motherhood" group. The mode of delivery was spontaneous or at most requiring manual help in $71.3 \%$ (83.4\%; $85.8 \%$ ) in the "control" group, but only in 51.4\% (72.2\%; $76.4 \%$ ) in the "late motherhood" group. Five-minute APGAR scores were likewise worse for neonates of "late" mothers and the proportion with a birth weight $\leq 2499 \mathrm{~g}$ was greater.

Conclusion: "Late motherhood" that is associated with greater perinatal risks can be defined based on parity and preterm birth rate.

\section{Zusammenfassung \\ $\nabla$}

Zielstellung: „Späte Mutterschaft“ ist verbunden mit größeren perinatalen Risiken, der Begriff ist aber nicht genau definiert. Hier wird eine Herangehensweise beschrieben, um zu bestimmen, was „späte“, mit höheren Risiken verbundene Mutterschaft ist, basierend auf Parität und Frühgeborenenrate.

Material und Methoden: Aufgrund von Daten der Deutschen Perinatalerhebung der Jahre 19982000 wurden Frühgeborenenraten bei Frauen mit keinen, einer oder zwei vorausgegangenen Lebendgeburten analysiert. Gruppen von „späten“ Müttern (mit hohen Frühgeborenenraten) wurden verglichen mit „Kontrollgruppen“ jüngerer Frauen (mit relativ niedrigen Frühgeborenenraten). Daten von 208342 Frauen wurden analysiert. Für Schwangere mit keinen (einer; zwei) vorausgegangenen Lebendgeburten umfasste die „Kontrollgruppe“ Frauen im Alter von 22-26 (27-31; 29-33) Jahren. Frauen in der Gruppe „später“ Mütter waren > 33 (> 35; > 38) Jahre alt.

Ergebnisse: Die Gruppen „später“ Mütter, die über eine erhöhte Frühgeburtlichkeit definiert wurden, hatten auch ein erhöhtes Risiko für andere ungünstige perinatale Outcomes. Für Frauen mit keinen (einer; zwei) vorausgegangenen Lebendgeburten fand sich eine regelrechte Schädellage bei $89 \%$ (92,7\%; 93,3\%) in der „Kontrollgruppe“, aber nur bei 84,5\% (90\%; 90,4\%) in der Gruppe der „späten“ Mütter. Der Entbindungsmodus war spontan bzw. Manualhilfe notwendig bei $71,3 \%(83,4 \% ; 85,8 \%)$ in der „Kontrollgruppe“, aber nur bei $51,4 \%$ (72,2\%; 76,4\%) in der Gruppe der „späten“ Mütter. Der 5-minütige APGARScore war ebenfalls schlechter bei den Neugeborenen „später“ Mütter, und der Anteil mit einem Geburtsgewicht $\leq 2499 \mathrm{~g}$ war größer. 
Schlussfolgerung: Die mit größeren perinatalen Risiken verbundene „späte Mutterschaft“ kann aufgrund von Parität und Frühgeborenenrate definiert werden.

\section{Introduction}

$\nabla$

"Late motherhood" (at least for singleton pregnancies) is associated with adverse perinatal and later outcomes for mother and child [1-9]. Among the risks associated with "late motherhood" is an increased preterm birth rate [10-11]. This can to some extent be explained with the age-dependent distribution of risk factors for preterm birth [12]. Preterm birth is an important risk because of its unfavourable clinical implications and because it is associated with substantial costs $[13,14]$.

However, it is unclear when precisely pregnant women should be labelled "old" and what should constitute "late motherhood". This is especially important as maternal age at birth is increasing, at least in the developed world. Many healthy children are now born to mothers aged beyond 35 and beyond 40 years $[2,15]$.

We believe parity should be considered in deciding what is "late" and what is not. The same maternal age may be perceived old for women having their first child but not old for women having their second or third child.

Preterm birth rates vary with age and parity. The relationship between maternal age and preterm birth rates is biphasic. The rates of preterm delivery are high for very young women and also for older women with the lowest rates being observed for women of intermediate age. What the "intermediate" age range associated with the lowest preterm birth rates is, depends on parity. The "optimal age" for delivery - from the perspective of being associated with the lowest preterm birth rates - is earlier for women giving birth to their first child than for women giving birth to their second or third child. Likewise, the "high risk" age range, when the preterm birth rate increases substantially with maternal age, occurs earlier for women having their first child compared with women giving birth to a later child $[10,11]$.

Our approach presented in this paper is to use the preterm birth rate to determine what is "late motherhood" for women of a given parity. We aimed to contrast a "late motherhood" group of women at high risk of preterm birth with a "control" group of younger pregnant women with low preterm birth rates. We analysed perinatal outcomes other than preterm delivery in these groups to see if the groups also differed consistently with regard to other perinatal risks. To take account of the effect of parity we conducted analyses separately for women with zero, one, or two previous live births.

\section{Materials and Methods \\ $\nabla$}

We had available data on singleton pregnancies from the routine data collection of the German Perinatal Survey of the years 19982000. Datasets contained a range of parameters of the pregnant women and their neonates, including maternal age, parity and perinatal outcomes. Data collection had been undertaken with standardised forms throughout Germany. Datasets were kindly provided to us by the chambers of physicians of the German federal states Bavaria, Brandenburg, Hamburg, Mecklenburg-Vorpommern, Lower Saxony, Saxony, Saxony-Anhalt, and Thuringia. To take account of the effect of parity we analysed data separately for women with zero, one, or two previous live births. We com- pared "late motherhood" groups of older, "high risk" pregnant women - defined by increased preterm birth rates - with "control" groups of younger pregnant women - defined by lower preterm birth rates. 0 Fig. 1 illustrates the way in which the high risk, "late motherhood" groups and the low risk "control" groups of younger pregnant women were formed. The groups were defined separately for women with no ( $\nabla$ Fig. 1 a), one ( $\nabla$ Fig. 1 b), and two ( Fig. 1 c) previous live births. In each case the "control" group included women in the age range (over 5 years) associated with low preterm birth rates, i.e. in-between the relatively high preterm birth rates seen in young women and in older women. The 'late motherhood' group was defined by the age range associated with rising preterm birth rates. Overall 208342 women were included in "late motherhood" and "control" groups.

We also subdivided "late motherhood" groups further according to age to assess risk in very old pregnant women. Odds ratios (OR) were calculated; numbers in brackets after the OR represent the 95\% confidence interval. Statistical analysis was assisted by SPSS (Version 15.0.1, Computer Centre of the University of Rostock, Germany).

\section{Results}

$\nabla$

The "late motherhood" groups of older pregnant women and "control" groups of younger pregnant women differed with regard to several important characteristics that are associated with increased perinatal risk. Selected parameters are illustrated in - Table 1. The table also shows the proportion of women with previous infertility treatment. As expected, this was highest in older women with no previous live births.

- Fig. 2 compares the birth presentations in the "late motherhood" and "control" groups for women with no ( $\bullet$ Fig. 2 a), one ( Fig. 2b), and two ( Fig. 2c) previous live births. The groups were defined as in $\bullet$ Fig. 1. The "late motherhood" groups always had a lower frequency of normal cephalic presentations and increased rates of other birth presentations compared with the "control" groups. Likewise, regarding the mode of delivery, the "late motherhood" groups had lower rates of spontaneous delivery or delivery requiring at most manual help and higher rates of other modes of delivery compared with the "control" groups (๑ Fig. 3). Subdividing the "late motherhood" groups further by age, we found that - for women with no or one previous live birth - the proportion with a spontaneous delivery or delivery requiring manual help decreased even further with increasing age. For women without previous live births the proportion with spontaneous delivery or requiring manual help was $52.1 \%$ for women aged $34-40$ years and $36.9 \%$ for women aged $41-46$ years (OR 1.9). For those with one previous live birth the difference was less: $72.7 \%$ for women aged $36-41$ years and $62.5 \%$ for women aged $42-47$ years (OR 1.6). For women with two previous live births there was no age dependence within the "late motherhood" group with regard to the proportion of women with a spontaneous delivery or requiring manual help: $76.4 \%$ for women aged 39-43 years and $76.0 \%$ for women aged $44-47$ years (OR 1.0). However, note the relatively low case number in the last subgroup (๑ Table 1). 
Table 1 Risk factors for adverse perinatal outcomes in the "control" and "late motherhood" groups. The groups were defined as in $\bullet$ Fig. 1 with the "late motherhood" groups of older women subdivided further according to age. Data are presented separately for women with zero, one, or two previous live births.

\begin{tabular}{|c|c|c|c|c|}
\hline $\begin{array}{l}\text { Previous } \\
\text { live births }\end{array}$ & Characteristic & $\begin{array}{l}\text { "Control" groups } \\
\text { (younger women) }\end{array}$ & $\begin{array}{l}\text { "Late motherhood" groups } \\
\text { (older women) }\end{array}$ & \\
\hline \multirow[t]{7}{*}{ Zero } & Age & $22-26$ years $(n=73812)$ & $34-40$ years $(n=21020)$ & $41-46$ years $(n=959)$ \\
\hline & Preterm birth rate & $6.5 \%$ & $9.0 \%$ & $13.0 \%$ \\
\hline & Previous stillbirths & $0.3 \%$ & $0.8 \%$ & $1.4 \%$ \\
\hline & Previous miscarriages & $9.1 \%$ & $19.9 \%$ & $33.6 \%$ \\
\hline & Previous terminations of pregnancy & $5.4 \%$ & $10.1 \%$ & $12.6 \%$ \\
\hline & Previous extrauterine pregnancies & $0.6 \%$ & $1.9 \%$ & $3.1 \%$ \\
\hline & Previous infertility treatment & $1.4 \%$ & $9.5 \%$ & $12.9 \%$ \\
\hline \multirow[t]{7}{*}{ One } & Age & $27-31$ years $(n=70037)$ & $36-41$ years $(n=15564)$ & $42-47$ years $(n=704)$ \\
\hline & Preterm birth rate & $4.2 \%$ & $7.0 \%$ & $10.7 \%$ \\
\hline & Previous stillbirths & $0.6 \%$ & $1.2 \%$ & $1.3 \%$ \\
\hline & Previous miscarriages & $17.3 \%$ & $29.1 \%$ & $40.8 \%$ \\
\hline & Previous terminations of pregnancy & $8.4 \%$ & $12.4 \%$ & $16.1 \%$ \\
\hline & Previous extrauterine pregnancies & $1.3 \%$ & $2.3 \%$ & $3.3 \%$ \\
\hline & Previous infertility treatment & $1.1 \%$ & $2.8 \%$ & $4.1 \%$ \\
\hline \multirow[t]{7}{*}{ Two } & Age & $29-33$ years $(n=22347)$ & $39-43$ years $(n=3720)$ & $44-47$ years $(n=179)$ \\
\hline & Preterm birth rate & $5.3 \%$ & $9.5 \%$ & $12.3 \%$ \\
\hline & Previous stillbirths & $0.9 \%$ & $1.5 \%$ & $1.7 \%$ \\
\hline & Previous miscarriages & $23.5 \%$ & $33.4 \%$ & $36.9 \%$ \\
\hline & Previous terminations of pregnancy & $12.9 \%$ & $18.9 \%$ & $22.3 \%$ \\
\hline & Previous extrauterine pregnancies & $1.7 \%$ & $2.4 \%$ & $1.1 \%$ \\
\hline & Previous infertility treatment & $0.5 \%$ & $1.3 \%$ & $2.2 \%$ \\
\hline
\end{tabular}

The proportions of women with a second stage of labour longer than 10 minutes were higher in the "late motherhood" groups (๑ Fig. 4). The rates of neonates with a low birth weight $(\leq 2499 \mathrm{~g})$ were likewise greater in the "late motherhood" groups compared with the "control" groups (defined as in Fig. 1): $8.2 \%$ vs. 5.3\% (OR 1.61 [1.52-1.70]) for women with no previous live births, 5.4 vs. 3\% (OR 1.83 [1.69-1.99]) for women with one previous live birth, and 7.5 vs. 3.8\% (OR 2.07 [1.80-2.38]) for women with two previous live births. Five-minute Apgar scores were also lower for children of women in the "late motherhood" groups. The proportions of children with an APGAR score of 8 or below were 9.3 vs. $7.9 \%$ (OR 1.19 [1.13-1.25]) for the "late motherhood" vs. "control" groups of women with no previous live births, 7.1 vs. $5.2 \%$ (OR 1.37 [1.28-1.47]) for women with one previous live birth, and 8 vs. 5.6\% (OR 1.46 [1.28-1.66]) for women with two previous live births (all groups as in $\bigcirc$ Fig. 1 ).

\section{Discussion}

In this paper high risk, "late motherhood" groups of older pregnant women and low risk "control" groups were formed based on preterm birth rates and parity. We found that these groups of women also differed with regard to other important perinatal outcomes including birth presentation, mode of delivery, and duration of the second stage of labour [16]. Our analysis may therefore be of help in defining what is "late motherhood" [17].

There are, however, some limitations to our approach. Most importantly, it was a retrospective, explorative analysis. The decision what is a high or low preterm birth rate for women of a given parity was made arbitrarily, based on the age dependence of preterm birth rates. Cut-points different to those chosen by us would also have been possible. Some important limitations arise because we were limited to data collected as part of the routine German Perinatal Survey. We could not verify the accuracy of the data and found that some data sets were incomplete. This ac- counts for the differences in the case numbers between analyses. Incomplete sets and some degree of data entry errors are inevitable in studies of this size. Furthermore, some information, for example on previous deliveries, was obtained from the medical history [18]. Where communication was difficult due to language barriers, it is conceivable that such information may have been obtained incorrectly. We also had no information on the postnatal development of the children. This would have been an important outcome. Women having children late differ from those having children early with regard to socioeconomic characteristics $[19,20]$; this was not considered in the present paper. Therefore, our analysis needs to be replicated in other populations and in prospective studies before rigorous definitions of high and low risk groups can be arrived at [21].

To define what is "late motherhood" needs to take preterm birth rate and parity into account, but it also needs to consider other risks to mother and child and the relative importance of these risks [22]. Furthermore, positive aspects of "late motherhood" should be considered. Birth at later maternal age can mean birth into a more secure socioeconomic environment.

Interestingly, the outcome for multiple pregnancies appears not to be inferior in women of advanced age compared with younger mothers. A recent study from Belgium even found that for twin pregnancies there was a lower incidence of preterm birth and low birth weight in primiparae aged 35 or over compared with primiparae aged 25-29 years [23]. A study from the United States also found that among primiparae giving birth to twins, older women had a lower risk of very preterm delivery than women aged 25-29 years [24]. A study from Greece compared twin pregnancies in women aged 35 years and older vs. women younger than 35. It found that for duration of pregnancy and birth weight there were no significant differences between younger and older mothers, though the rate of infants with a very low birth weight (less than $1500 \mathrm{~g}$ ) was significantly higher for the older women [25]. An older age at the last birth is also associated with longer 


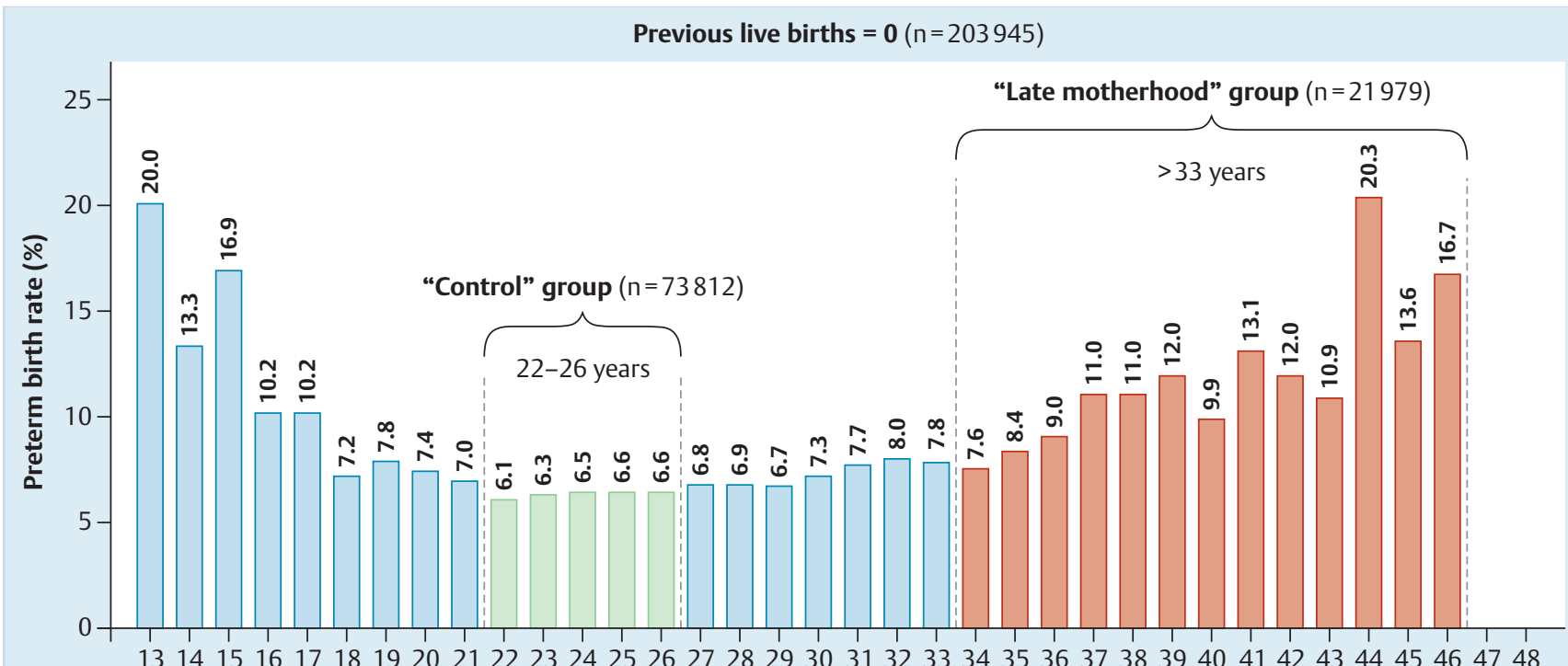

a Maternal age (years)

Previous live births $=\mathbf{1}(\mathrm{n}=168177)$
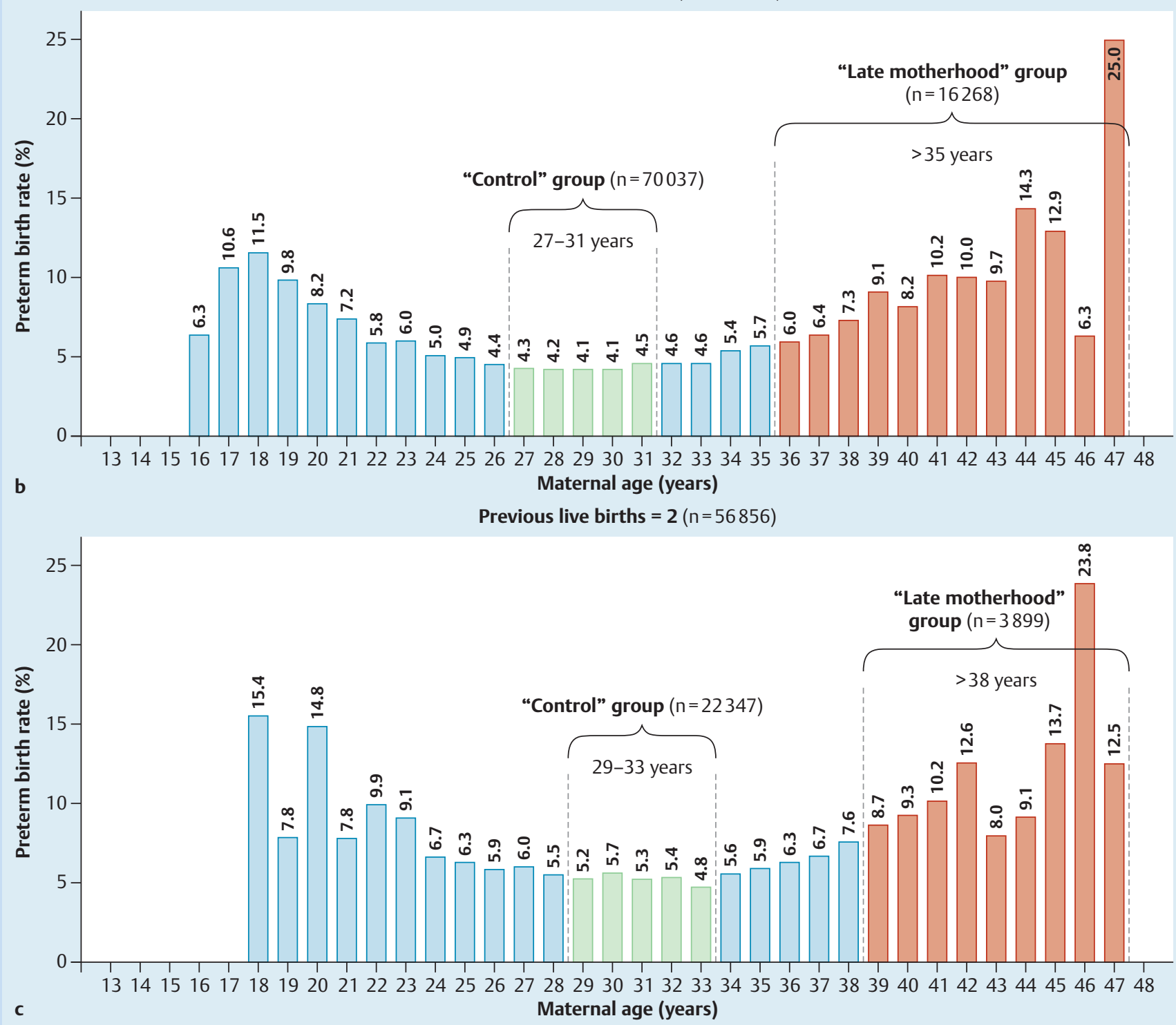

Fig. 1 a to c Defining the "late motherhood" and "control" groups for women with no (a), one (b), and two (c) previous live births. In each case the "control" group was defined by the maternal age range (over 5 years) associated with low preterm birth rates and the "late motherhood" group by the age range associated with high preterm birth rates. 


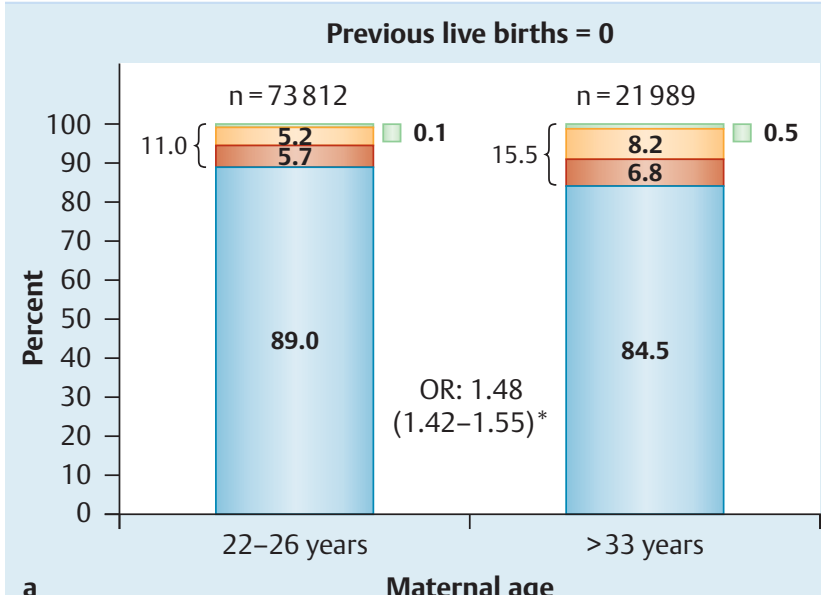

a

\section{Maternal age}

\section{Previous live births $=1$}

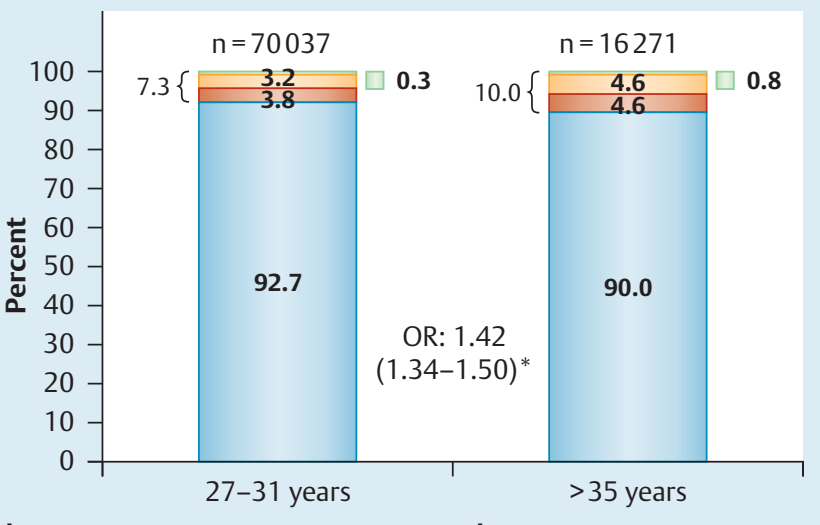

b

\section{Maternal age}

\section{Previous live births $=2$}

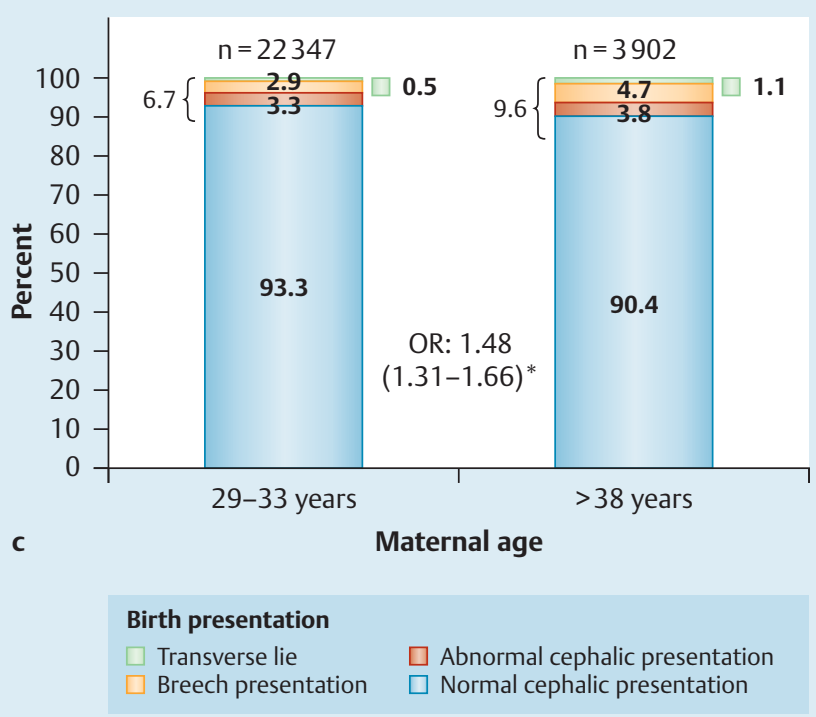

Fig. 2 a to c Birth presentations in the "late motherhood" and "control" groups for women with no (a), one (b), and two (c) previous live births; groups were as defined in 0 Fig. 1. OR - odds ratio (with $95 \%$ confidence interval); ${ }^{*}$ indicates statistical significance.

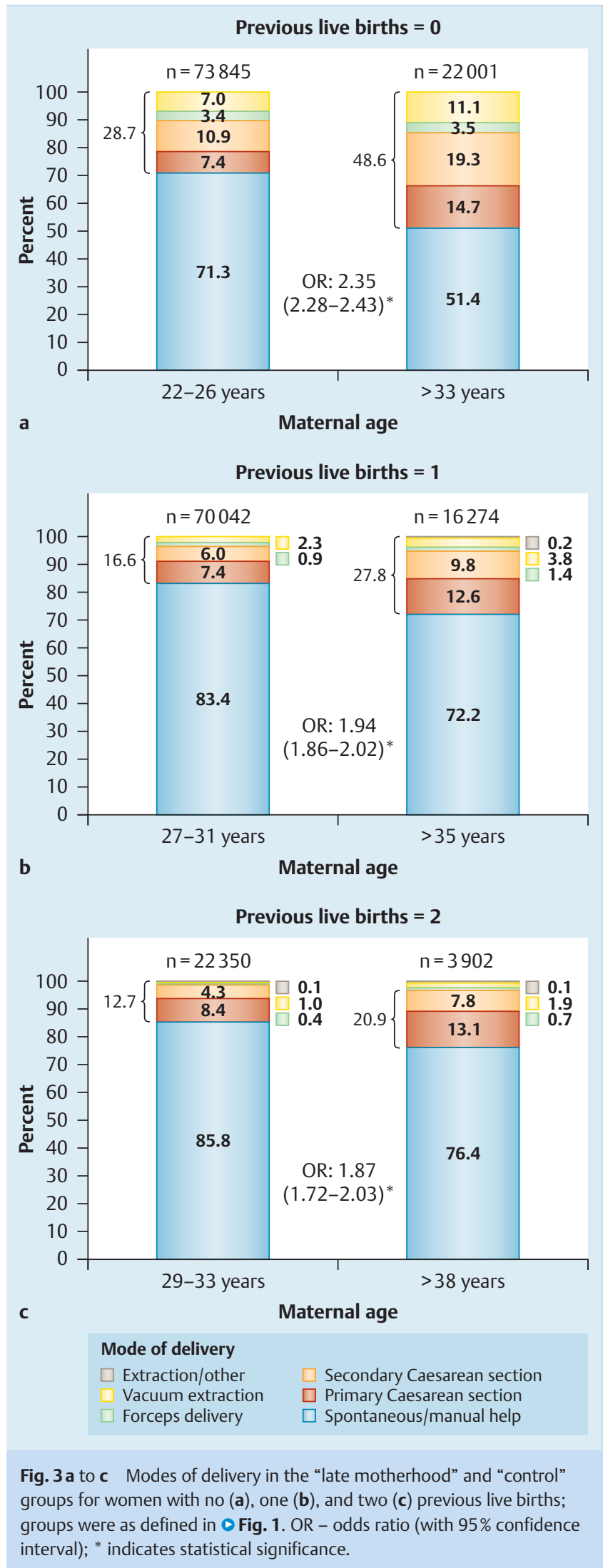




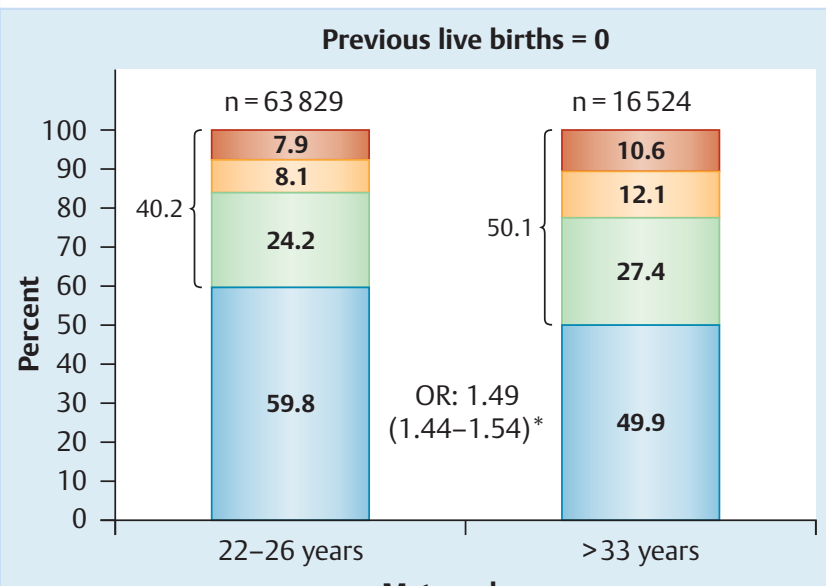

a

Maternal age

Previous live births $=1$

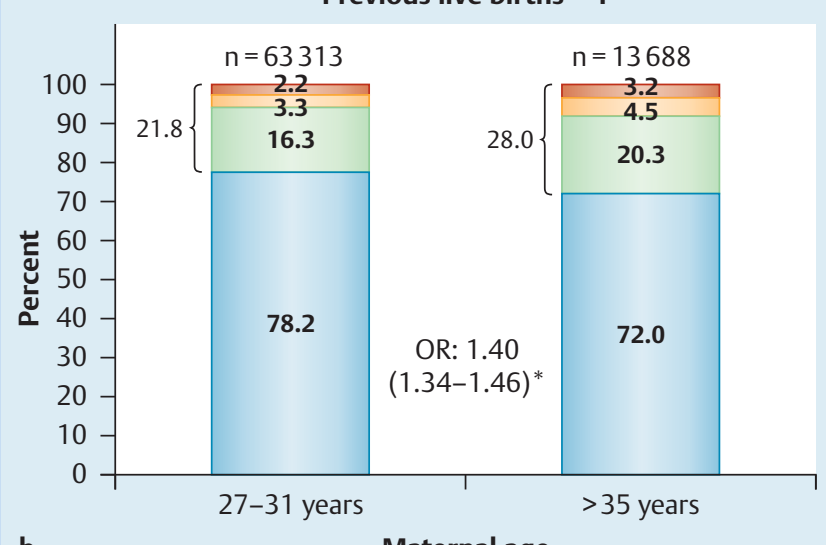

b

Maternal age

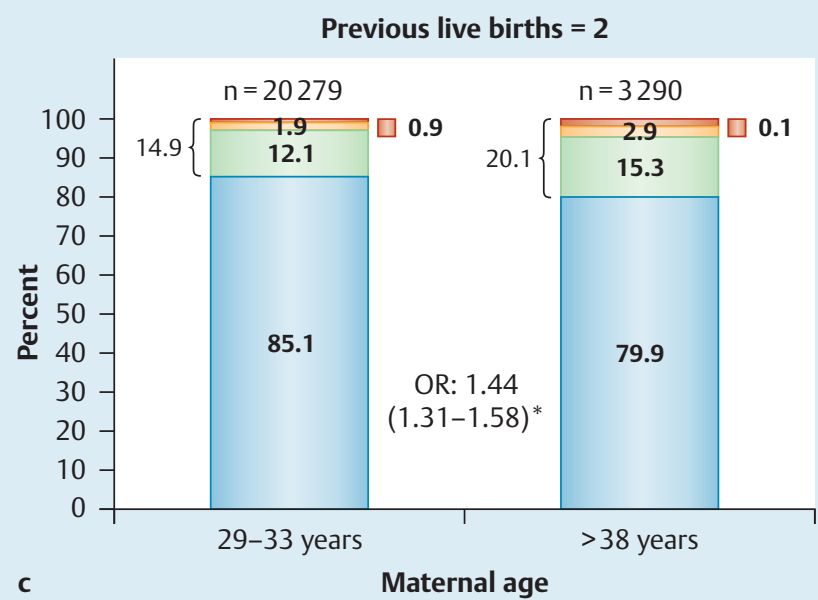

Duration of the second stage of labour ( $\mathrm{min})$
$\square 0-10$
$\neg 11-20$
$\square$ 21-30
$\square>30$

Fig. 4 a to $c$ Duration of the second stage of labour (in minutes) in the "late motherhood" and "control" groups for women with no (a), one (b), and two (c) previous live births; groups were as defined in $\odot$ Fig. 1. OR odds ratio (with $95 \%$ confidence interval); ${ }^{*}$ indicates statistical significance. maternal life span [26,27], though this may be due to genetic make-up rather than the effects of a late pregnancy [28].

Plenty of evidence confirms higher perinatal risks in older mothers and their infants [29]. Some studies indicate that good perinatal outcomes can be achieved for older women [30], even in postmenopausal women becoming pregnant after in vitro fertilization with donor oocytes [31]. However, even though in some studies selected perinatal parameters may not appear inferior for older vs. younger mothers, on a population level perinatal risks are clearly higher in older women. Furthermore assisted reproduction in older women often is undertaken in selected, i.e. comparatively healthy, women.

Despite the above-mentioned limitations, we are confident that our analysis contributes to determining what is "late motherhood" from a risk perspective. Future work will need to take this approach further.

\section{Conflict of Interest}

$\nabla$

None.

\section{References}

1 Huang L, Sauve R, Birkett $N$ et al. Maternal age and risk of stillbirth: a systematic review. CMAJ 2008; 178: 165-172

2 Montan S. Increased risk in the elderly parturient. Curr Opin Obstet Gynecol 2007; 19: 110-112

3 Usta IM, Nassar AH. Advanced maternal age. Part I: obstetric complications. Am J Perinatol 2008; 25: 521-534

4 Nassar AH, Usta IM. Advanced maternal age. Part II: long-term consequences. Am J Perinatol 2009; 26: 107-112

5 Lampinen $R$, Vehviläinen-Julkunen K, Kankkunen P. A review of pregnancy in women over 35 years of age. Open Nurs J 2009; 3: 33-38

6 Schoen C, Rosen T. Maternal and perinatal risks for women over $44-\mathrm{a}$ review. Maturitas 2009; 64: 109-113

7 Voigt M, Rochow N, Zygmunt $M$ et al. Risks of pregnancy and birth, birth presentation, and mode of delivery in relation to the age of primiparous women. Z Geburtshilfe Neonatol 2008; 212: 206-210

8 Straube $S$, Voigt $M$, Jorch $G$ et al. Investigation of the association of Apgar score with maternal socio-economic and biological factors: an analysis of German perinatal statistics. Arch Gynecol Obstet 2010; 282: $135-141$

9 Rath WH. Definitions and diagnosis of postpartum haemorrhage (PPH): underestimated problems! Geburtsh Frauenheilk 2010; 70: $36-40$

10 Straube S, Voigt M, Scholz R et al. 18th communication: preterm birth rates and maternal occupation - the importance of age and number of live births as confounding factors. Geburtsh Frauenheilk 2009; 69: 698-702

11 Voigt M, Briese V, Pietzner V et al. Evaluierung von mütterlichen Merkmalen als Risikofaktoren für Frühgeburtlichkeit (Einzel- und Kombinationswirkung). Z Geburtshilfe Neonatol 2009; 213: 138-146

12 Voigt $M$, Briese $V$, Carstensen $M$ et al. Age-specific preterm birth rates after exclusion of risk factors - an analysis of the German Perinatal Survey. Z Geburtshilfe Neonatol 2010; 214: 161-166

13 Behrman RE, Butler AS; Institute of Medicine (US) Committee on Understanding Premature Birth and Assuring Healthy Outcomes, editors. Preterm Birth: Causes, Consequences, and Prevention. Washington, DC: National Academies Press (US); 2007

14 Voigt M, Straube S, Fusch C et al. Erhöhung der Frühgeborenenrate durch Rauchen in der Schwangerschaft und daraus resultierende Kosten für die Perinatalmedizin in Deutschland. Z Geburtshilfe Neonatol 2007; 211: 204-210

15 Heffner LJ. Advanced maternal age - how old is too old? N Engl J Med. 2004; 351: 1927-1929

16 Simoes E. Informed consent for cesarean delivery: method-associated morbidity gradients require the participation of pregnant women. Geburtsh Frauenheilk 2010; 70: 732-738

17 Beyer DA. Pregnancy risks and infant morbidity after assisted reproduction. Geburtsh Frauenheilk 2010; 70: 30-35 
18 Haager-Burkert $H$. Perceived difficulties for clinics with maternity units in Germany in obtaining the certification "Baby Friendly Hospital". Geburtsh Frauenheilk 2010; 70: 726-731

19 Toulemon $L$. Who are the late mothers? Rev Epidemiol Sante Publique 2005; 53 (Spec No 2): 2S13-2S24

20 Hartge DR. Gravidas with a BMI above 25: challenges in antenatal and peripartal monitoring. Geburtsh Frauenheilk 2010; 70: 463-471

21 Gawlik S. Prenatal depression and anxiety - what is important for the obstetrician? Geburtsh Frauenheilk 2010; 70: 361-368

22 Billmann $M-K$. Pregnancies at an advanced maternal age: results from Zurich and review of the literature. Geburtsh Frauenheilk 2010; 70: 273-280

23 Delbaere I, Verstraelen H, Goetgeluk S et al. Perinatal outcome of twin pregnancies in women of advanced age. Hum Reprod 2008; 23: 2145-2150

24 Branum AM, Schoendorf KC. The influence of maternal age on very preterm birth of twins: differential effects by parity. Paediatr Perinat Epidemiol 2005; 19: 399-404

25 Prapas N, Kalogiannidis I, Prapas I et al. Twin gestation in older women: antepartum, intrapartum complications, and perinatal outcomes. Arch Gynecol Obstet 2006; 273: 293-297
26 Müller HG, Chiou JM, Carey JR et al. Fertility and life span: late children enhance female longevity. J Gerontol A Biol Sci Med Sci 2002; 576: B202-B206

27 McArdle PF, Pollin TI, O'Connell JR et al. Does having children extend life span? A genealogical study of parity and longevity in the Amish. J Gerontol A Biol Sci Med Sci 2006; 61: 190-195

28 Smith KR, Gagnon A, Cawthon RM et al. Familial aggregation of survival and late female reproduction. J Gerontol A Biol Sci Med Sci 2009; 64: 740-744

29 Salihu HM, Shumpert MN, Slay M et al. Childbearing beyond maternal age 50 and fetal outcomes in the United States. Obstet Gynecol 2003; 102: 1006-1014

30 Ziadeh S, Yahaya A. Pregnancy outcome at age 40 and older. Arch Gynecol Obstet 2001; 265: 30-33

31 Paulson RJ, Boostanfar R, Saadat P et al. Pregnancy in the sixth decade of life: obstetric outcomes in women of advanced reproductive age. JAMA 2002; 288: 2320-2323 